\title{
Assessment of quality of life in patients treated for low-grade glioma: a preliminary report
}

M J B Taphoorn, J J Heimans, F J Snoek, J Lindeboom, B Oosterink, J G Wolbers, A B M F Karim
Free University Hospital, Amsterdam, The Netherlands, Department of Neurology M J B Taphoorn J J Heimans B Oosterink

Department of Medical Psychology

F J Snoek

$\mathrm{J}$ Lindeboom

Department of Neurosurgery J G Wolbers

Department of Radiotherapy A B M F Karim

Correspondence to: Dr Taphoorn, Department of Neurology, Free niversity Hospital, PO Box 7057, 1007 MB Amsterdam The Netherlands.

Received 4 June 1991 and in revised form Accepted 24 September 1991

\begin{abstract}
In this pilot study quality of life was assessed in fourteen adult patients who were treated for a low-grade glioma with surgery and radiotherapy at least one year previously. Apart from widely used parameters, such as the neurological and functional status, the patients' cognitive functioning and actual affective status were determined. In addition the patients were interviewed to evaluate various aspects of quality of life. Generally no serious focal neurological deficits were found, although psychological examination showed serious cognitive and affective disturbances in most cases. Self report measures concerning cognitive functioning were not in all cases in accordance with objective test results. When the results of treatment in glioma patients are evaluated assessment of quality of life, including neuropsychological functioning, should be performed, especially as new therapeutic strategies are being developed.
\end{abstract}

In most studies on efficacy of treatment for low-grade glioma time to tumour recurrence or duration of survival are used as end points. Retrospective analyses indicate that both duration of survival and time to tumour progression are prolonged by radiotherapy. ${ }^{1-3}$ Radiotherapy may on the other hand bring about long term side effects, with regard to brain functioning. ${ }^{4-6}$ Prospective studies will need to be performed to find the optimal treatment of low-grade glioma. This issue is still being discussed. ${ }^{7-9}$

Notwithstanding conceptual and methodo-

Table 1 Patient characteristics

\begin{tabular}{|c|c|c|c|c|c|c|c|}
\hline \multicolumn{3}{|c|}{ Patient } & \multicolumn{2}{|l|}{ Tumour } & \multicolumn{2}{|l|}{ Treatment } & \multirow{2}{*}{$\begin{array}{l}\text { Interval to } \\
R T \text { (months) }\end{array}$} \\
\hline Case & Age & $M / F$ & Location & Pathol ${ }^{\star \star}$ & Surgery & $R T(c G y)$ & \\
\hline $\begin{array}{l}1 \\
2 \\
3 \\
4 \\
5 \\
6 \\
7 \\
8 \\
9 \\
10 \\
11 \\
12 \\
13 \\
14\end{array}$ & $\begin{array}{l}41 \\
61 \\
66 \\
37 \\
34 \\
37 \\
24 \\
26 \\
61 \\
40 \\
47 \\
39 \\
40 \\
42\end{array}$ & $\begin{array}{l}\mathbf{M} \\
\mathbf{F} \\
\mathbf{F} \\
\mathbf{M} \\
\mathbf{M} \\
\mathbf{M} \\
\mathbf{M} \\
\mathrm{F} \\
\mathbf{F} \\
\mathbf{M} \\
\mathbf{M} \\
\mathbf{M} \\
\mathbf{M} \\
\mathbf{M}\end{array}$ & $\begin{array}{l}\text { L temp } \\
\mathbf{L} \text { pariet } \\
R \text { pariet } \\
\mathbf{L} \text { temp } \\
\mathbf{L} \text { front } \\
\mathbf{L} \text { pariet } \\
\mathrm{L} \text { thalam } \\
\mathrm{R} \text { pariet } \\
\mathrm{L} \text { temp } \\
\mathrm{L} \text { pariet } \\
\mathrm{L} \text { front } \\
\mathrm{R} \text { thalam } \\
\mathrm{L} \text { front } \\
\mathrm{L} \text { pariet }\end{array}$ & $\begin{array}{l}\text { oligo B } \\
\text { oligo A } \\
\text { astro II } \\
\text { astro II } \\
\text { astros!II } \\
\text { astro II } \\
\text { astro I } \\
\text { astro II } \\
\text { oligo B } \\
\text { astro II } \\
\text { astro II } \\
\text { astro II } \\
\text { oligo B } \\
\text { oligo A }\end{array}$ & $\begin{array}{l}\text { subtotal } \\
\text { biopsy } \\
\text { subtotal } \\
\text { subtotal } \\
\text { subtotal } \\
\text { subtotal } \\
\text { biopsy } \\
\text { gross tot } \\
\text { gross tot } \\
\text { biopsy } \\
\text { gross tot } \\
\text { biopsy } \\
\text { rad.subt } \\
\text { biopsy }\end{array}$ & $\begin{array}{l}4500 \\
6120 \\
5940 \\
4500 \\
5400 \\
5000 \\
4500 \\
4500 \\
5400^{\star} \\
5940 \\
5940 \\
5400 \\
5940 \\
5400\end{array}$ & $\begin{array}{r}46 \\
80 \\
12 \\
14 \\
108 \\
24 \\
49 \\
24 \\
13 \\
51 \\
46 \\
12 \\
43 \\
135\end{array}$ \\
\hline
\end{tabular}

Patient 9 had been irradiated before ( $3960 \mathrm{cGy})$

$\star \star$ Tumour grading according to Kernohan ${ }^{14}$ and Smith logical controversies, quality of life evaluation has become increasingly important for clinical decision making. ${ }^{10}$ In studies on treatment for low-grade glioma, however, systematic information on the quality of life of these patients is scarce. ${ }^{11}$ Quality of life in cancer patients is best defined as a multidimensional concept that encompasses the physical, emotional and social components associated with the illness and its treatment. ${ }^{1213}$ To measure quality of life as defined above, an extensive assessment is required, using both objective and subjective indices. In this pilot study the well-being of 14 patients was assessed in a comprehensive somato-psychological examination, including their physical functioning, affective status, social functioning, cognitive functioning and sense of general well-being. The primary aim of this study was to evaluate the utility of the instruments to be used for future studies.

\section{Patients and methods \\ Patients}

Adult patients (>18 years of age), who had been treated for a low-grade supratentorial glioma with surgery and radiotherapy at least one year previously were included. Only patients without clinical or CT signs of tumour recurrence were included. All 14 patients who met these criteria were asked to participate: all 14 could be tested.

Seven patients took fenytoin and three patients valproate to prevent fits; serum levels of these drugs were within the therapeutic range. No drugs that might influence mood, such as corticosteroids or antidepressants were taken by the patients. Pituitary stimulation tests and hypothalamic functions tested in 12 of the 14 patients were normal. In table 1 the 
characteristics of the 14 patients included are described; in addition data are given on the tumour and the treatment. ${ }^{1415}$ Mean age of the group (10 males, four females) was 43.4 years (24-66 years). All patients had surgery: five biopsy, six subtotal removal and three gross total removal. One patient (case 9) had a right hemiparesis and an aphasia which were not influenced by surgery. No significant abnormalities were found in the other patients on neurological examination, both before and after surgery. Postoperative focal brain radiotherapy (4 or $6 \mathrm{MeV}$ photons) was given to all patients. The total dose ranged from 4500 to $6120 \mathrm{cGy}$; the number of fractions varied between 25 to 34 , given in 30 to 54 days.

\section{Methods}

A neurological examination (including orientation and alertness, cranial nerves, motor and sensory functions, reflexes and coordination) was performed on all patients and the Karnofsky Performance Status (KPS) was determined. To detect possible cognitive deficits, attentional, mnestic, verbal, visuo-spatial and executive functions were tested. For this purpose 8 standardised tests were used (table 2), ${ }^{16-23}$ which took about 45 minutes.

On the basis of the patients' performances on the various tests, a Total Cognitive Problem Score (TCPS) was calculated, serving as an overall index of cognitive dysfunction. The TCPS is a mean score based on ratings of each subtest performance on a 3 point scale, from 0 (normal), 1 (lowered) to 2 (disturbed).

The patients were subsequently interviewed by a clinical psychologist, using a questionnaire, which was developed especially for this patient group by one of the authors (FS) and served as a guideline for a structured interview that took approximately 45 minutes. It focused on a) Social-economic status; b) Physical complaints; c) Problems with daily life activities, including cognitive functioning; d) Social functioning and perceived social support; e) Evaluation of the overall health status and wellbeing and $f$ ) Treatment experiences and outlook.

In 11 cases the partners were present to supply additional information on daily problems and worries of the patients as well as themselves.

In addition patients were psychologically tested to measure their actual affective status, using the Affect Balance Scale (ABS) ${ }^{24}$ and the Dutch version of the Profile of Mood States (POMS). ${ }^{25}{ }^{26}$ The ABS is a widely used instrument for measuring "happiness" in health surveys and studies on Quality of Life and consists of 10 yes/no items. ${ }^{27}$ The concept of "happiness" is operationally defined as the experience of more positive affect than negative affect over the past three weeks. The affect balance is simply calculated as the positive affect score $(0-5)$ minus the negative affect score (0-5). The POMS is a more sophisticated mood-adjective checklist, commonly used in studies on subjective well-being. ${ }^{28}$ The Dutch version of the POMS measures affective disturbances along five dimensions, namely depression, anger, fatigue, tension and vigour. It consists of 32 items to be scored by the patient with respect to the past few days, on a 5-point Likert-scale ranging from "not at all" to "very much". The total somato-psychological assessment was completed in one session and took approximately $2 \frac{1}{2}$ hours.

\section{Results}

Neurological examination

On neurological examination two patients had abnormalities: patient 2 had a clearly disturbed orientation in time and place; patient 9 had a severe right hemiparesis and an expressive aphasia. All other patients were normal on neurological examination. KPS in patient 2 was 70; in patient 9 it was 40 . In the other patients KPS was at least 80 .

\section{Neuropsychological assessment}

Most disturbances were found on the StroopColour Word Test 3 (interference), the Rey-test (immediate recall) and the $\mathrm{d} 2$ total score (selective concentration). The results of these three tests are shown in table 3, together with the TCPS based on all subtest performances.

The relationship between the data gathered from the neuropsychological examination and subjective reports that were obtained in the structured interview is demonstrated in table 4. Patients rated the degree of difficulty they experienced in memorising and concentration in daily life on a 3-point scale: "no difficulty" (0), "some difficulty" (1), "a lot of difficulty" (2). By splitting the TCPSs around the median ( 7 cases with score $0 \cdot 69-1 \cdot 21 ; 6$ cases with

Table 2 Neuropsychological tests

\begin{tabular}{|c|c|}
\hline Test & Function \\
\hline $\begin{array}{l}\text { d2-Test } \\
\text { (Brickenkamp, 1967) } \\
\text { Stroop-colour-Word Task } \\
\text { (Stroop, 1935) } \\
\text { Rey Auditory-Verbal Learning Test } \\
\text { (Rey, 1959) } \\
\text { Visual Association Test } \\
\text { (Lindeboom, 1989) } \\
\text { Categoric Word retrieval } \\
\text { (Talland, 1965) } \\
\text { Judgement of Line Orientation } \\
\text { (Benton et al, 1978) } \\
\text { Facial recognition test } \\
\text { (Hamsher et al, 1979) } \\
\text { WISC Maze Test } \\
\text { (Wechler, 1949) }\end{array}$ & $\begin{array}{l}\text { selective concentration } \\
\text { exclusive concentration } \\
\text { immediate and delayed recall } \\
\text { episodic memory } \\
\text { verbal fluency } \\
\text { spatial insight } \\
\text { gestalt recognition } \\
\text { foresight and planning }\end{array}$ \\
\hline
\end{tabular}


Table 3 Cognitive functioning: Total Cognitive Problem Score and level of impairment in 3 sub-tests

\begin{tabular}{lllll}
\hline \multicolumn{2}{l}{ Cognitive tests } & & & \\
\hline Cases & TCPS & Stroop-Color & Rey-test & $d 2$-test \\
\hline 1 & 0.69 & 2 & 2 & 0 \\
2 & 1.07 & 2 & 2 & 2 \\
3 & 1.21 & 2 & 1 & 1 \\
4 & 0.86 & 2 & 2 & 2 \\
5 & 0.00 & 0 & 0 & 0 \\
6 & 0.29 & 2 & 0 & 1 \\
7 & 1.07 & 2 & 1 & 2 \\
8 & 0.07 & 0 & 0 & 0 \\
10 & 1.21 & 0 & 2 & 2 \\
11 & 0.29 & 2 & 1 & 0 \\
12 & 1.00 & 0 & 0 & 2 \\
13 & 0.50 & 2 & 1 & 2 \\
14 & 0.50 & 2 & 2 & 0 \\
\hline
\end{tabular}

Patient 9 could not be tested (severe aphasia) TCPS: Total Cognitive Problem Score (range 0-2)

$0=$ normal

$=$ normal
$1=$ lowered

$2=$ disturbed

score $0-0.55)$ one group with high and one group with low cognitive impairment was created. As shown in table 4 these two groups do not differ in the mean level of self-reported problems with concentration and memory. In other words, in the 13 patients tested no correlation was found between objective test results and self-report measures on cognitive functioning. Seven patients rated themselves more cognitively disturbed than indicated by test results while two patients severely underestimated their impairments.

\section{Structured interview}

It became evident from the interview that fatigue was the most prominent physical complaint (12 cases), together with sleepiness (10 cases). Table 5 gives an overview of the patients' subjective complaints during the past four weeks, rated on a 3-point scale from "no trouble" to "troublesome".

Four patients $(2,10,13$ and 14) stated with emphasis in their interview to be unsatisfied with their overall health status. With the exception of patients 3,6 and 12 the whole group had experienced significant personality changes after surgery and radiotherapy, generally described as increased emotional reactivity and lowered tolerance for stressful situations. The partners of the patients underlined this pattern of behavioural change which in some cases had contributed to social isolation. The partner's view on the patient's daily life functioning was generally more critical than the patient's own view. After surgery six
Table 4 Comparison of subjective memory and concentration in the low and high impaired group on cognitive functioning $(N=13)$

\begin{tabular}{llllll}
\hline & \multicolumn{2}{c}{ Memory } & & \multicolumn{2}{c}{ Concentration } \\
\cline { 2 - 3 } \cline { 5 - 6 } TCPS & mean & $S D$ & & mean & $S D$ \\
\hline $0.69-1.21$ & 1.3 & $(0.8)$ & & 1.0 & $(0.6)$ \\
$0.00-0.55$ & 1.3 & $(0.8)$ & & 1.0 & $(0.9)$ \\
\hline
\end{tabular}

TCPS = Total Cognitive Problem Score

patients were treated for their psychosocial problems related to the glioma. Overall, patients and partners expressed satisfaction with the care offered at the hospital and felt they had been informed sufficiently at the start of treatment.

\section{Affective status}

When asked about the sense of general wellbeing, that is, an overall evaluation of how the patient felt in the past three weeks, on a scale from 1 to 5 ("very bad"-"very good"), three patients answered neutral ("not good, not bad"), while the others stated to feel "good" and "very good".

Scores on the ABS show that only in two cases (10 and 14) negative affect predominated over positive affect (table 6). Results on the POMS, however, indicate that, compared with the normal population, the group studied here on the average showed high scores on depression, anger, fatigue and tension, and scored low on vigour.

\section{Discussion}

Recently it was stated that, with patients treated for brain glioma, more attention should be paid to the impact of treatment on brain functions, using quality of life, neuropsychological functioning and electroencephalography as parameters. ${ }^{29}$

In this study an extensive assessment of quality of life, along various dimensions, took place. With the test procedure itself, none of the patients examined considered the examination too demanding or tiring. This shows that an extensive assessment in glioma-patients is feasible. Several discrepancies were demonstrated between the collected data.

In only two patients widely used parameters, such as the neurological and functional performance status, showed significant dysfunction. On the other hand, tests for cognitive

Table 5 Physical complaints $(N=13)$

\begin{tabular}{|c|c|c|c|c|c|c|c|c|c|c|c|c|c|}
\hline \multirow[b]{2}{*}{ Complaints } & \multicolumn{13}{|c|}{ Cases } \\
\hline & 1 & 2 & 3 & 4 & 5 & 6 & 7 & 8 & 10 & 11 & 12 & 13 & 14 \\
\hline Fatigue & + & ++ & ++ & + & ++ & - & + & ++ & ++ & + & ++ & ++ & ++ \\
\hline Dizziness & - & - & - & - & - & - & - & + & + & - & - & + & - \\
\hline Nausea & - & - & - & - & - & - & - & - & + & - & - & - & - \\
\hline Headache & - & + & + & - & - & - & - & + & + & - & - & ++ & - \\
\hline Fits & - & - & - & - & - & + & - & - & - & - & - & - & + \\
\hline Sleepiness & + & + & - & - & - & + & + & ++ & ++ & + & ++ & + & + \\
\hline Sexual problems & - & - & - & - & ++ & - & - & - & - & - & - & - & + \\
\hline Sleep disturbance & + & ++ & + & - & - & ++ & - & - & + & + & - & - & - \\
\hline
\end{tabular}


Table 6 Affective status (N=l3): discrepancy beween ABS and POMS

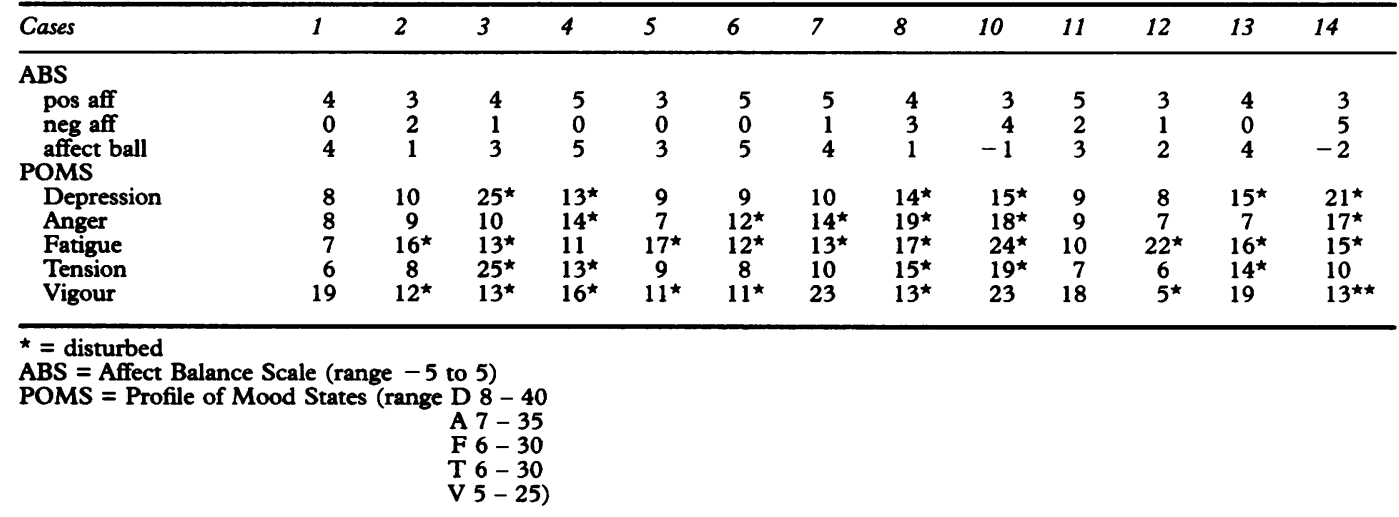

functioning and the affective status were abnormal in nearly all patients. In two earlier studies marked neuropsychological impairment was demonstrated in adult patients treated for brain tumours. Hochberg and Slotnick evaluated cognitive functioning in 13 patients surviving for at least one year after treatment for astrocytoma with surgery, radiotherapy and chemotherapy. ${ }^{30}$ Maire et al studied 49 adult patients with primary intercranial tumours, following surgery and radiotherapy. ${ }^{31}$ Both studies, as well as ours, were performed on a selected population without premorbid testing. According to these studies radiotherapy was suspected to be the main cause of neuropsychological deficits, especially in learning new tasks which require attention and immediate solving ability.

In only two of our patients (7 and 11) deficits on cognitive testing could be related to the location of the tumour.

The lack of this relation in most of our patients is in favour of diffuse, radiationrelated disturbances, although it has been suggested that the relationship between the involved structures and specific cognitive defects is less evident for brain tumour than for stroke: brain dysfunction caused by a tumour may partly be due to displacement of neuronal structures rather than to destruction as is the case in stroke. ${ }^{32}$ In view of the assumed heterogeneity of both origin and severity of cognitive disturbances due to a broad spectrum of functions and locations potentially affected by the tumour and the treatment, the various neuropsychological tests were chosen.

Besides objective neuropsychological testing, subjective complaints concerning cognitive dysfunctioning were evaluated in the interview. Especially in view of the growing interest of the impact of medical treatment on the subjective well-being, the discrepancy demonstrated between the objective and subjective data is an interesting phenomenon, that deserves further research. Of special interest is the question of whether information on the premorbid level of cognitive functioning could explain the fact that some patients experience their cognitive functioning as more impaired than would be expected on the basis of test results.

In his study no premorbid testing was possible, but the neuropsychological tests results were interpreted taking into consideration the patients' educational level and age, which is a relatively accurate estimate of the premorbid level.

The partner's view on the patient's functioning generally seemed more in accordance with test results than the patient's own view. Data obtained from the patient's direct environment may therefore be an important source of information, next to the patients' own reports.

The results of the ABS indicated a negative affect balance in only two patients. On a more superficial level the patients are obviously not unhappy, but results on the POMS showed evident signs of depression, anger, fatigue, tension and lack of vigour in 11 of the 13 patients examined. This is also reflected by the results of the structured interview on common physical complaints such as fatigue, sleepiness and sleep disturbances. On the other hand, only two patients taking antiepileptic drugs complained of partial seizures occurring two or three times a year. The mood disturbances mentioned above may have influenced the results on neuropsychological testing which was also demonstrated in a recent paper. ${ }^{33}$ Moreover, mood disturbances may also explain the overestimation of cognitive deficit in several patients. These mood disturbances may be caused by brain damage as a result of radiation, but also by a combination of diffuse brain damage and psychological problems in terms of adjustment and fear of tumour recurrence.

The ABS, together with questions asking the patient to give a global evaluation of their wellbeing, appears to give us only superficial information about the emotional status of glioma patients. Further studies are necessary to determine whether the disturbances of cognitive functions and quality of life as observed in these patients are due to the tumour, surgery, radiotherapy or even other causes. Important patient and treatment variables are, for example, length of follow up, radiation dose and fraction size. For this purpose other groups of patients need to be tested, such as, patients with low-grade glioma who have not been treated with radiotherapy, and patients with malignancies without CNS involvement.

We argue that, apart from a neurological 
examination and assessment of the functional status, neuropsychological testing (with special attention for concentration and immediate recall), as well as an evaluation of the actual affective status and a structured interview are required when the impact of treatment on the quality of life in glioma patients is evaluated. This applies especially to patients without significant disturbances of the neurological and functional performance status. In this patient group the ABS appears to be of limited use: it gives little additional information to the POMS and may be omitted in future studies. Moreover, the Visual Association Test could potentially be omitted as similar information is obtained from the D-2 test. The length of the interview may in our opinion be reduced by combining some parts and using more precoded questions. In this way the quality of life assessment can be shortened.

1 Garcia DM, Fulling KH, Marks JE. The value of radiation therapy in addition to surgery for astrocytomas of the adult cerebrum. Cancer 1985;55:910-27.

2 Shaw EG, Daumas-Dupont C, Scheithauer BW et al. Radiation therapy in the management of low-grade supratentorial astrocytomas. $f$ Neurosurg 1989;70: 853-61.

3 North CA, North RB, Epstein JA, Piantadosi S, Wharam MD. Low-grade cerebral astrocytomas: survival and quality of life after radiation therapy. Cancer quality of $1990 ; 66: 6-14$.

4 Sheline GE, Wara WM, Smith V. Therapeutic irradiation and brain injury. Int $\mathcal{f}$ Radiat Oncol Biol Phys 1980; 6:1215-28.

5 DeAngelis LM, Delattre J-Y, Posner JB. Radiation-induced dementia in patients cured of brain metastases. Neurology 1989;39:789-96.

6 Al-Mefty O, Kersh JE, Routh A, Smith RR. The long-term side effects of radiation therapy for benign brain tumors in adults. $\mathcal{F}$ Neurosurg 1990;73:502-12.

7 Cairncross JG, Laperrière NJ. Low-grade glioma: to treat or not to treat? Arch Neurol 1989;46:1238-9.

8 Shaw EG. Low-grade gliomas: to treat or not to treat? A radiation oncologist's viewpoint. Arch Neurol 1990; 47:1138-9.

9 Cairncross JG, Laperrière NJ. Low-grade gliomas: to treat or not to treat? A reply. Arch Neurol 1990;47:1139-40.

10 Patrick DL Erickson P. Assessing health-related quality of life for clinical decision making. In: Walker SR, Rosser RM, eds. Quality of life: assessment and application. The Hague: MTP Press, 1988.
11 Karim ABMF. Cure and quality of life after treatment for glioma. In: Karim ABMF, Laws ER, eds. Glioma: principles and practice in neurooncology. Springer Verlag Heideiberg: Springer Verlag, 1991 (in press).

12 Najman JM, Levine S. Evaluating the impact of medical care and technologies on the quality of life: a review and critique. Soc Sci Med 1981;15F:105-15.

13 Haes JCM, Knippenberg FE van. The quality of life of cancer patients. A review of the literature. Soc Sci Med cancer patients.

14 Kernohan JW, Sayre GP. Tumors of the central nervous system. Atlas of Tumor Pathology, section $X$, fascicles 35 and 36. Washington DC: Armed Forces Institute of Pathology, 1952.

15 Smith MT, Ludwig CL, Godfrer AD, Armbrustmacher VW. Grading of oligodendrogliomas. Cancer 1983;52: 2107-44.

16 Stroop JR. Studies of interference in serial verbal reactions. f Exp Psychol 1935;18:643-62.

17 Wechsler D. Wechsler Intelligent Scale for Children. New York, NY: The Psychological Corp, 1949.

18 Rey A. Sollicitation de la mémoire de fixation par des mots et des objets présentés simultanément. Archives de Psychologie 1959;37:126-39.

19 Talland GA. Deranged memory. New York, NY: Academic Press, 1965.

20 Brickenkamp R. Test d 2. Aufmerksamkeits-Belastungs-Test. Göttingen: Verlag fur Psychologie dr CJ Hogrefe.

1 Benton L, Varney NR, Hamsher K. Visuospatial judgment: clinical test. Arch Neurol 1978;35:364-7.

22 Hamsher K, Levin HS, Benton AL. Facial recognition in patients with focal brain lesions. Arch Neurol 1979; 36:837-9.

23 Lindeboom J. Measurement of anterograde amnesia. $7 \mathrm{Clin}$ Exp Psy 1989;11:345 (abstr).

24 Bradburn NM. The structure of psychological well-being. Chicago: Aldine Publishing Company, 1969.

25 McNair DM, Lorr M, Droppleman LF. Manual for the Profile of Mood States. San Diego: Educ and Industr Testing Service, 1971.

26 Wald F. De verkorte POMS. (Doct Thesis) University of Amsterdam, 1984

27 Larsen RJ, Diener E, Emmons RA. An evaluation of subjective well-being measures. Social Indicators Research 1985;17:1-17.

28 Underwood B and Froming WS. The Mood survey: A personality measure of happy and sad moods. $\mathcal{f}$ Personality Assessm 1980;44:404-14.

29 Choucair AK. Proposals for evaluation of toxic effects associated with treatment of gliomas: a call for action. $\mathcal{f}$ Nat Cancer Institute 1990;82:531-2.

30 Hochberg FH, Slotnick B. Neuropsychological impairment in astrocytoma survivors. Neurology 1980;30:172-7.

31 Maire JPh, Coudin B, Guérin, Caudry M. Neuropsychological impairment in adults with brain tumors. Am $f$ Clin Oncol 1987;10:156-162.

32 Anderson SW, Damasio H, Tranel D. Neuropsychological impairments associated with lesions caused by tumor or impairments associated with lesions caus

33 Danion J-M, Willard-Schroeder D,Zimmermann M-A, et al. Explicit memory and repetition priming in depression. Preliminary findings. Arch Gen Psychiatry 1991;48: 707-11. 